\title{
CAEFE USP e a importância da organização estudantil como potencializadora dos direitos humanos
}

https://doi.org/10.11606/issn.1981-4690.v35inespp55-62

\author{
Pedro Henrique Rodrigues do Vale* \\ Júlia Silveira Marante* \\ Marcos Kauê Ferreira de Queiroz* \\ Sergio Roberto Silveira* \\ *Escola de Educação \\ Física Esporte, \\ Universidade de São \\ Paulo, São Paulo, SP, \\ Brasil.
}

\begin{abstract}
Resumo
0 Centro Acadêmico da Escola de Educação Fisica e Esporte da Universidade de São Paulo (CAEFE USP) foi fundado em 15 de dezembro de 1955 com o nome de Centro Acadêmico Ruy Barbosa (até 2019). Desde então, participa ativamente da construção da vida acadêmica junto aos setores da universidade. A Declaração Universal dos Direitos Humanos (DUDH) foi aprovada na Assembleia Geral das Nações Unidas, em dezembro de 1948 e dai em diante sofre ameaças e violações, sendo necessária a atuação de vários segmentos da sociedade a fim de assegurar e potencializar os direitos contidos em seu teor. A universidade é um sítio de inovação, mas também pode refletir mazelas sociais. Pretende-se, neste ensaio, relacionar as ações desenvolvidas pelo CAEFE USP a partir da ótica de ações que potencializem os Direitos Humanos (DH). Após contextualização a respeito da temática e do movimento estudantil, são expostas algumas ações do CAEFE-USP, relacionando-as diretamente com Artigos da Declaração. Com isso, visa-se entender a maneira que o CAEFE-USP ratifica e promove os DH, assim como a forma que a DUDH norteia e fundamenta as ações do CAEFE USP.
\end{abstract}

Palavras-chave: Direitos humanos; Movimento estudantil; Educação Física.

\section{Introdução}

O Centro Acadêmico de Educação Física e Esporte USP (CAEFE USP) é a entidade de representação dos estudantes da Escola de Educação Física e Esporte da Universidade de São Paulo. Criado em 15 de dezembro de 1955, completou, em 2020, 65 anos de existência. Funcionou, também, como uma entidade aberta à participação, proporcionando um ambiente rico para relações interpessoais, experiências e aprendizados.

Pretende-se, neste ensaio, relacionar ações desenvolvidas pelo CAEFE a partir de atividades que potencializam preceitos contidos na Declaração Universal dos Direitos Humanos $(\mathrm{DUDH})^{1}$. As ações do Movimento Estudantil (ME) atuam na manutenção dos $\mathrm{DH}$, assim como os $\mathrm{DH}$ fundamentam agremiaçóes como as organizaçóes estudantis do ME. Para tanto, pretende-se reconstruir historicamente certas ações do ME até a atuação específica do CAEFE, explicitando sua relação na potencialização dos DH.

Desde sua implementação, em 1948, a DUDH e suas diretrizes têm sofrido sérias ameaças e violaçôes. Um exemplo disso foi todo o processo inverso das liberdades individuais e dos direitos civis das pessoas que viveram sob o regime militar no Brasil, dentre outras ditaduras vividas pelo mundo. Pretende-se, assim, reforçar a importância de debater os DH na atualidade, além de resgatar seu prestígio e origem fraternal.

Nos últimos anos, espaços dentro da EEFE foram criados para discussão da temática dos $\mathrm{DH}$ e devem ser valorizados, uma vez que contribuem diretamente para reflexôes como as que aqui serão apresentadas. Citamos a implementação do Núcleo de Direitos Humanos da Escola de Educação Física e Esporte da USP² e o trabalho de sua atual gestáo ${ }^{3}$ que promove a criação de um evento que de maneira muito 
positiva pretende reunir docentes, discentes, pesquisadores e pesquisadoras para refletir e

\section{Direitos humanos}

A Declaração Universal dos Direitos Humanos (DUDH) foi aprovada em Assembleia Geral das Naçôes Unidas a 10 de dezembro de 1948, póssegunda guerra mundial ${ }^{1}$. Os 30 artigos descritos na declaração são considerados direitos fundamentais para a manutenção da vida e da dignidade humana. Eles asseguram desde direitos elementares, como ter "garantia à vida, à liberdade e à segurança pessoal" $\left(\right.$ Artigo $3^{\circ}$ ), até concepçôes que permeiam as ações comuns no dia a dia, como o "direito a repouso e lazer, inclusive à limitação razoável das horas de trabalho e a férias remuneradas periódicas" (Artigo 24º).

Desde sua declaração, os DH vêm sofrendo ameaças e violaçóes que ocorrem tanto em casos isolados, quanto em situaçóes onde essa violaçáo se encontra à nível estrutural, como por exemplo, no regime do Apartheid na África do Sul, que perdurou de 1948 à 1994, assegurado por uma política oficial no país ${ }^{4}$.

No que se refere ao asseguramento dos direitos do movimento estudantil pode-se destacar os artigos:

Art $1^{\circ}$ - "Todos os seres humanos nascem livres e iguais em dignidade e direitos. São dotados de razão e consciência e devem agir em relação uns aos outros com espírito de fraternidade." Art $26^{\circ}$ - "1. Todo ser humano tem direito à instrução. A instrução será gratuita, pelo menos nos graus elementares e fundamentais. A instrução elementar será obrigatória. A instrução técnicoprofissional será acessível a todos, bem como a instrução superior, esta, baseada no mérito.

2. A instrução será orientada no sentido do pleno desenvolvimento da personalidade humana e do fortalecimento do respeito pelos direitos do ser humano e pelas liberdades fundamentais. A instrução promoverá a compreensão, a tolerância e a amizade entre todas as naçóes e grupos raciais ou religiosos e coadjuvará as atividades das Naçóes Unidas em prol da manutenção da paz. 3. Os pais têm prioridade de direito na escolha do gênero de instrução que será ministrada a seus filhos."

Art. $27^{\circ}$ - " 1 . Todo ser humano tem o direito de participar livremente da vida cultural da compartilhar conhecimentos acerca da educação física e esporte face às premissas dos DH. comunidade, de fruir as artes e de participar do progresso científico e de seus benefícios.

2. Todo ser humano tem direito à proteção dos interesses morais e materiais decorrentes de qualquer produção científica literária ou artística da qual seja autor."

Tais artigos legitimam a luta do ME no que diz respeito à garantia de direitos, principalmente no âmbito da educação e da cultura, importantes pautas abraçadas pelo movimento estudantil. Dados referentes à última Pesquisa Nacional por Amostra de Domicílios (PNAD) realizada pelo IBGE em 2015, ${ }^{5}$ apontam que, no Brasil, 177.657 pessoas de 10 anos ou mais ainda são analfabetas, em total detrimento com o Artigo $26^{\circ}$. Outro exemplo é a falta ou restrição de acesso a equipamentos culturais por parte das minorias. Em outra pesquisa realizada pelo IBGE em $2018^{6}$, mostra que, no Brasil, $74.6 \%$ das pessoas que se identificam como brancas residem em municípios com existência de museus, em contraste com os $62,5 \%$ de pessoas que se identificam enquanto pretas e pardas.

Mesmo sendo um local já avançado na discussão sobre igualdade de gênero, combate ao racismo e outros tópicos dignos de atenção, a universidade ainda é um local onde ocorrem violações aos $\mathrm{DH}$. Uma infeliz realidade que mostra essas violaçôes é a taxa de violência contra mulheres dentro do campus da USP: de todas as pessoas que responderam um questionário on-line, 55\% daquelas que se autodeclaram mulheres já sofreram ou sofrem algum tipo de violência, seja ela moral, física ou sexual ${ }^{7}$. Essa realidade mostra uma infração aos DH mais básicos, como à igualdade (artigo $1^{\circ}$ ) e à liberdade e segurança pessoal $\left(\operatorname{artigo~} 3^{\circ}\right)$.

\section{Histórico do movimento estudantil brasileiro}

O ME brasileiro já passou por diversas fases e ainda representa influente participação na vida política do país. Em seu início, não possuía entidades gerais e era caracterizado apenas por açóes individuais. Com o passar do tempo, esses indivíduos passaram a se organizar e lutar por um objetivo em 
comum definido, o que deu início à criação das entidades estudantis 8 .

A fundação do primeiro Centro Acadêmico (CA), entidade que representa os estudantes de um curso ou faculdade, ocorreu em 11 de agosto de 1903 e deu origem ao chamado Centro Acadêmico XI de Agosto, que é o órgão representativo dos discentes da Faculdade de Direito do Largo de São Francisco, em São Paulo. Após sua fundação, diversos outros CAs se organizaram, como o "Centro Acadêmico Hugo Simas", fundado em 1908 pelos estudantes do curso de Direito da Universidade Federal do Paraná. ${ }^{9}$

Sob a necessidade da criaçáo de uma entidade bem estruturada que organizasse a luta estudantil a nível nacional, foi criada, em 11 de agosto 1937, a União Nacional dos Estudantes (UNE) ${ }^{10}$. Foi durante esse mesmo período que as primeiras Escolas de Educação Física civis foram criadas, representando um marco para o início da formação em educação física e a futura criação do Movimento dos Estudantes de Educação Física $(\mathrm{MEEF})^{11}$.

Desde o início do seu surgimento, o movimento estudantil trabalha ativamente em busca de uma melhor qualidade de ensino, assim como uma sociedade mais justa e democrática. No MEEF, o estopim para a fundação de uma organização estudantil se deu na década de 50, na antiga Escola Nacional de Educação Física (hoje UFRJ), onde o diretor tinha várias ocupações e na avaliação dos estudantes não dedicava o tempo necessário que a escola exigia. A instituição não possuía piscina em suas instalaçóes e as aulas de natação ocorriam no Clube Guanabara. Após um dos estudantes ser impedido de frequentar as aulas, pois o clube náo aceitava a entrada de pessoas negras, os estudantes se organizaram, com apoio de outras faculdades vizinhas (medicina, farmácia, arquitetura e odontologia) e fizeram uma forte mobilização, que desencadeou uma greve que durou meses e teve repercussão nos jornais da época. $\mathrm{O}$ movimento saiu vitorioso: uma comissão de estudantes foi recebida pelo então presidente Juscelino Kubitschek e tiveram o apoio financeiro para construçáo de uma piscina na escola. O diretor, pressionado, optou por sua aposentadoria ${ }^{12}$. Após esse episódio o MEEF também se organizou em uma entidade geral, a atual Executiva Nacional dos Estudantes de Educaçáo Física (ExNEEF), que segue atuando até hoje e organiza o Encontro Nacional dos Estudantes de Educação Física (ENEEF) e os Encontros Regionais de Estudantes de Educação Física (EREEFs).

No dia 01 de abril de 1964, um golpe instaurou uma ditadura civil-militar no Brasil que perdurou até 1985. Durante esse período, muitos direitos sociais e trabalhistas foram dissolvidos, assim como atos inconstitucionais instaurados, que na prática permitiram a censura de veículos de imprensa, além de perseguiçáo política, tortura e morte de opositores. Com isso, fica evidente que a ditadura foi um período de graves violaçóes aos $\mathrm{DH}$. Dentre todos os grupos que se organizaram na luta contra a ditadura, o ME destaca-se por ter cumprido um papel fundamental nesse enfrentamento. Isso graças à participação em protestos, passeatas, lutas armadas, panfletagens e outras formas de resistência. É possível ver a expressividade da participação dos(as) estudantes em uma análise realizada pela Comissão da Verdade do Estado de Sáo Paulo "Rubens Paiva", que levantou a condição política das pessoas que foram mortas durante esse regime: das 436 pessoas que estão no Dossiê dos Mortos e Desaparecidos Políticos elaborado pela Comissão de Familiares de Mortos e Desaparecidos Políticos, 125 eram estudantes, demonstrando que os atores do movimento estudantil muito incomodava a ditadura e, por isso, foram um dos seus principais alvos de perseguição ${ }^{13}$.

A Ditadura enxergou diretamente o ME como inimigo, dado primeiramente pelo próprio histórico da UNE na defesa da democracia, do petróleo e das reformas de base. Inclusive o "[...] primeiro ato do golpe foi incendiar a sede da UNE, prender toda a diretoria e retirar sua legalidade através da Lei Suplicy de Lacerda, e assim a mesma passou a existir como uma oposição ao regime" ${ }^{14}$ (p.8).

Os motivos mais plausíveis do porquê os movimentos organizados de estudantes eram vistos como ameaças ao regime militar são os papéis que esses órgãos têm na produção de debates acerca de tópicos politicamente relevantes, tais como, combate ao racismo, liberdades individuais, igualdade de gênero, formação de senso crítico e, principalmente, na resistência a tudo aquilo que ameace os $\mathrm{DH}$, ou seja, resistência a grande parte das ações tomadas durante o regime.

Em 29 de maio de 1979, a UNE anuncia seu retorno por meio de seu XXXI Congresso o congresso de sua reconstruçáo. Esse acontecimento foi um importante marco para o retorno do $\mathrm{ME}$ para o palco político nacional ${ }^{8}$.

\section{CAEFE USP: uma entidade para representaçáo e formaçáo estudantil}

Um CA é a entidade de representação dos estudantes de um curso ou de uma instituiçáo de ensino superior. Sua legalidade, assim como de outras entidades estudantis, no Brasil, é assegurada 
pela Lei 7.395 de 31 de outubro de 1985 que instituiu os órgãos representativos dos estudantes das instituiçóes de ensino superior e revoga outras 2 leis instauradas no período da ditadura militar, que proibiram e perseguiram as entidades e organizaçóes estudantis no país ${ }^{14}$.

Lei 7.395 de 31 de outubro de 1985

Dispóe sobre os órgãos de representação dos estudantes de nível superior e dá outras providências

Art. $1^{\circ}$ - A União Nacional dos Estudantes UNE, criada em 1937, é entidade representativa do conjunto dos estudantes das Instituiçōes de Ensino Superior existentes no País.

Art. $4^{\mathrm{o}}$ - Fica assegurado aos Estudantes de cada curso de nível superior o direito à organização de Centros Acadêmicos - CAs ou Diretórios Acadêmicos - DAs como suas entidades representativas.

Art. $7^{\circ}$ - Revogam-se as disposiçôes em contrário, especialmente as contidas na Lei $n^{\circ} 4.464$, de 9 de novembro de 1964 , e na Lei no 6.680 , de 16 de agosto de 1979.

O CAEFE USP foi fundado em 15 de dezembro de 1955, chamado Centro Acadêmico Ruy Barbosa (até 2019). Nesse período de 65 anos de existência, participou da construção da vida acadêmica junto aos setores da EEFE USP e enfrentou democraticamente as adversidades das situaçóes produzidas por gestores da instituição, governos e governantes.

A função de representar o corpo estudantil não é uma tarefa simples. Entender a estrutura organizacional da instituiçáo, tomar propriedade das discussōes, participar das reuniôes das comissôes e departamentos, dialogar e trazer consensos do corpo discente, organizar plenárias, estar em contato com outras entidades estudantis etc. Tudo isso requer comprometimento, organização e empenho. Parte da complexidade deste processo existe por conta da rotatividade na composição da entidade, seja por troca de gestão ou por renovação do corpo discente da instituição. Isso incide em um desafio constante: a integração e formação de novos membros (a fim de agilizar e potencializar os impactos da atuação destes na entidade). É relativamente comum que mesmo após anos ou décadas de fundação, membros de novas gestóes de CAs necessitem "começar do zero", aprender e estruturar do início a dinâmica da entidade estudantil. Esta ocorrência não é só pelas novas ocupaçóes, mas também pela ineficiente formação continuada para preparar os novos integrantes para assumir a gestão. Nota-se então que o CA é uma entidade que necessita de um eixo formativo em sua organização, a fim de garantir sua continuidade.

Para além de visualizar uma perspectiva formativa intrínseca, podemos evidenciar que a prática cotidiana da entidade resulta em benefícios na formação não só de seus diretores, mas de todos que têm contato com suas atividades. Por exemplo, quando o CAEFE promove um debate a respeito de determinado tema, muitos dos espectadores absorvem as reflexóes da discussão, neste momento cria-se a possibilidade de reconstruírem suas crenças, opiniôes e teorias. Desta forma, a atuação do CA resulta em possível formação e transformação. Portanto, promoçáo de debates, rodas de conversas, oficinas, plenárias, confraternizações e demais projetos do CA acabam sempre alcançando públicos externos à sua diretoria.

Esse processo é rico e com potencial formativo por vários ângulos. Um deles parte do entendimento de que o corpo estudantil constrói ativamente a universidade e logo, pode propor e executar projetos que sejam de seu interesse e que, de preferência, tenham um comprometimento social estabelecido. O CA é um espaço onde essas proposições são bemvindas e por sua característica coletiva, agrupa projetos com essas diretrizes.

\section{Atividades do CAEFE como potencializadoras dos direitos humanos}

O CAEFE discute constantemente propostas de futuras açóes e quais os seus efeitos para as pautas do corpo estudantil. Em cada uma das ações tem-se como objetivo criar um efeito positivo e reflexivo. Mesmo a ação mais simples tem intencionalidade de acumular e promover consciência acerca do que ocorre na unidade escolar, na universidade, no país e no mundo.

Serão ressaltadas três atividades, com características diferentes que estimularam o pensamento reflexivo e se relacionaram com a prática potencializadora do CAEFE em relaçáo aos DH: uma Assembleia Geral de Estudantes, uma Roda de Capoeira conduzida pelo grupo Mulheres da Garoa e a atuação acadêmica durante a pandemia de Covid-19.

A Assembleia Geral dos Estudantes da EEFE USP, que foi realizada no dia 13 de Maio de 2019, foi convocada pelo CAEFE após indicativo de paralisação aprovado na Assembleia Geral dos Estudantes da USP, realizada anteriormente pelo DCE Livre da USP. A plenária teve a participação de aproximadamente $20 \%$ do corpo estudantil da 
unidade e após um período de discussão sobre como a política adotada pelo governo federal naquele momento, de cortes e de contingenciamento dos recursos das universidades e institutos federais, afetaria a qualidade de ensino, além de comprometer a produção científica das IES financiadas pela Uniâo, logo, afetando a produção em todo o país. Aprovou-se praticamente por unanimidade a paralisação das atividades acadêmicas na Escola no dia 15 de maio de 2019, para que os estudantes pudessem organizar sua participação em bloco no ato convocado pela UNE em defesa da educação e da ciência brasileira. $\mathrm{O}$ estudante, $\mathrm{BP}$, ingressante de 2018 compartilha que:

"O 15M foi um dos meus primeiros movimentos de rua, que participei com efetividade e foi algo que eu jamais esquecerei. Dentro de todas as restriçóes tidas no momento, senti que estar ali junto com professores, estudantes, cientistas me fez uma pessoa diferente e que devemos buscar sempre os nossos poderes como cidadáos e não apenas simplesmente fingir que não nos afeta. Estar presente no dia 15 de maio foi muito importante como contribuição para minha vida pessoal e estudantil e espero estar sempre presente quando for necessário."

Esse evento é legitimado pelos artigos $18^{\circ}, 19^{\circ}$ e $20^{\circ}$ da DUDH os quais garantem, respectivamente, o direito à liberdade de pensamento e consciência, além de sua manifestação pelo ensino e pela prática em público ou em particular; direito à liberdade de opiniấo e expressão e o direito à liberdade de reuniáo e associação pacífica.

A Roda de capoeira conduzida pelo grupo Mulheres da Garoa, foi realizada no dia 17 de Maio de 2019, na EEFE USP, em comemoraçáo ao dia 13 de Maio (dia da abolição da escravatura). Sucedida no horário de almoço, contou com aproximadamente 70 participantes. Toda a atividade foi conduzida acompanhada por um vasto repertório de músicas e cantigas. Partiu-se da contextualização históricosocial, seguido de um momento para o aprendizado de movimentos básicos, finalizando com a roda de capoeira. Essa atividade foi importante pois resgata a história de luta e resistência dessa prática corporal de origem afro-brasileira, permitindo que todas as pessoas presentes tivessem contato com conhecimentos históricos a respeito dessa manifestação cultural e vivenciassem gestos, musicalidades e outras humanidades características da capoeira. Essa importância ganha ainda mais relevância em uma sociedade onde atividades de matriz africana são barbaramente oprimidas e desvalorizadas. Isto porque o conceito de racismo vem também "...através $d a$ referência cultural, resultando em culturas superiores e culturas inferiores; assim, conserva-se o processo de hierarquização entre a civilização branca europeia (cultura superior) e as civilizaçóes africanas e negras (cultura inferior)"16 (p.53).

Outro ponto que marcou a atividade, foi a condução atípica da roda. A prática da capoeira ainda é uma prática majoritariamente conduzida por homens e o evento trouxe uma nova perspectiva ao apresentar uma condução realizada por mulheres. Esse cenário resultou em questionamentos pertinentes e sobretudo foi a oportunidade de demonstrar o quanto a prática corporal pode ser crítica, propositiva e libertadora. A Estudante HP, do $3^{\circ}$ ano, relata suas sensaçóes ao participar desta atividade:

"Lembro-me da sensaçẫo de chegar num espaço para aprender um pouco mais sobre uma arte marcial, uma "luta", e esse espaço estar tomado majoritariamente por mulheres. Foi lindo e reconfortante ver mulheres ministrando e ensinando a outras mulheres movimentos herdados de nossa ancestralidade. Aprendemos alguns movimentos sozinhas, em duplas e em roda. Aos poucos as pessoas foram se soltando e ficando a vontade, entregues ao momento e às propostas das professoras. Uma das partes das quais mais gostei foi quando aprendemos algumas músicas de capoeira e cantamos juntas. Todas ganharam voz e assumiram o canto. Um canto que foi por muito tempo tirado de nós. Naquele dia me senti mais forte, enquanto mulher, enquanto futura educadora física, futura professora e treinadora. A oficina foi de grande valor, não só pelo protagonismo feminino, mas porque nos trouxe integração, diversão, trabalho coletivo e nos colocou em contato com cultura e conhecimentos riquíssimos, que são pouco difundidos nas instituiçóes formais de ensino. Há muita coisa que náo se aprende dentro da sala de aula (mas fora dela) eu, felizmente pude ver um pouco disso na oficina de capoeira."

A realização dessa atividade dialoga diretamente com o Artigo $27^{\circ}$ da DUDH, que assegura o direito à livre participação da vida cultural da comunidade.

Vale a pena ressaltar também a continuidade da atuação do CAEFE durante a pandemia de Covid-19, existente até o momento. Adaptando ou criando novas atividades no formato remoto, o CAEFE seguiu representando e movimentando os estudantes durante a quarentena. Desde o 
início da suspensão das atividades presenciais na universidade, representantes discentes dialogaram com a direção, com a comissão de graduação, com o comitê especial para açóes relacionadas à COVID-19 e com a comissão especial de apoio ao ensino remoto. Foi disponibilizado formulários online com o intuito de acolher o corpo estudantil, compreender as novas demandas e organizar as reivindicaçóes estudantis. Dentre as questóes levantadas durante as reuniôes com os dirigentes, foram debatidos tópicos como as adaptaçóes necessárias para as aulas remotas, período máximo para trancamento/exclusão de disciplinas e demandas de acesso a equipamentos e internet por parte de estudantes vulneráveis. O CAEFE ajudou a rastrear estes estudantes, orientá-los para recebimento de kits de internet oferecidos pela Pró-reitoria de Graduação e junto

\section{Perspectivas}

A partir das questóes levantadas neste ensaio, observam-se perspectivas para o CAEFE e para a área dos DH em Educação Física e Esporte.

A principal perspectiva para o CAEFE é o fortalecimento da relação com o Núcleo de Direitos Humanos da EEFE USP. Na atual composição do núcleo há membros da diretoria do CAEFE, o que certamente garantirá um diálogo mais dinâmico entre os dois coletivos. Sendo a universidade também um local de possíveis violaçóes dos $\mathrm{DH}$, faz-se necessário um alinhamento estratégico na produção de materiais e açôes educativas em $\mathrm{DH}$, ou seja, é necessário que ambos os coletivos se unam e promovam açóes em parceria, de modo que a conscientização em torno dos $\mathrm{DH}$ de fato se potencialize e tenha uma abrangência significativa, com reflexos na prática profissional e na vida acadêmica dos participantes.

\section{Considerações finais}

Por fim, fica evidente a importância do ME como potencializador dos $\mathrm{DH}$, sendo cada $\mathrm{CA}$ um possível potencializador local, debatendo e promovendo atividades educativas e informativas em $\mathrm{DH}$.

Essas açóes podem ou não serem realizadas em parceria com comissóes e núcleos de direitos humanos de cada unidade de ensino. $\mathrm{Na}$ ausência com a instituição promoveu uma campanha de doação de equipamentos eletrônicos, fornecendo os equipamentos doados para os estudantes que relataram dificuldades com seus equipamentos.

Além desse diálogo institucional, o CAEFE também criou conteúdo digital no formato de "lives informativas". Sempre com a condução de um discente, as lives do CAEFE abordaram temas como: "Divulgação científica na era das fake news", "O exercício físico em tempos de isolamento social" e "Acolhimento estudantil e saúde mental: agravantes do distanciamento social". Junto às lives, também foram organizados debates remotos sobre questóes políticas e sociais dentro do espectro da Educaçáo Física, como por exemplo o debate "Racismo estrutural e as práticas corporais". Essas atividades demonstram a pluralidade possível para atuações do CAEFE.

Para a área dos DH em Educação Física e Esporte, espera-se que a produçáo deste ensaio incite a produção de novos trabalhos que relacionem concepções presentes na DUDH com a atuação de CAs e demais organizaçóes estudantis. A realização do Seminário de Direitos Humanos em Educação Física e Esporte certamente muito contribuirá para o desenvolvimento de novos trabalhos relacionados, entretanto, vê-se necessário reforçar que o $\mathrm{ME}$ age também como potencializador de discussóes e trazer os DH para escopo destas discussões é papel do próprio corpo estudantil. Sendo assim, uma perspectiva promissora é o compartilhamento da temática em espaços do $\mathrm{ME}$, como por exemplo nos encontros estudantis regionais e nacional, verificar a existência de comissóes como o núcleo de direitos humanos em outras universidades e seguir estimulando o debate em todos esses níveis.

de um núcleo de $\mathrm{DH}$, o estímulo pode partir das organizaçóes estudantis para a sua criação com representaçáo de todos os segmentos da unidade. Isto porque, "qualquer unidade deve reconhecer a importância do papel de coletivos organizados entre os alunos, como visto nas diversas unidades onde eles se criaram e atuaram: eles ampliam o debate, 
conscientizam a comunidade, alinham discursos, são criativos no enfrentamento dos problemas" 2 (p.115).

O CAEFE USP durante as suas atividades dos últimos dois anos perpassou por pelo menos 12 Artigos da DUDH, potencializando, reafirmando e propagando os conceitos e as convicçóes da citada
Declaração. Sendo assim, o CAEFE é um ator direto na propagação dos $\mathrm{DH}$ dentro da vida acadêmica dos novos profissionais de Educação Física e Esporte do Brasil, trazendo reflexóes sobre a função da área para um país mais igualitário, com equidade, respeito, tolerância e reflexão.

\begin{abstract}
CAEFE USP as a important student organization and potentiating of the human rights

The Academic Center of the School of Physical Education and Sport from the University of São Paulo (ACPE USP) was founded in december 15, 1955 with the Academic name of the Center is: Ruy Barbosa (until 2019). Since then, it participates actively in the construction of academic life within other sectors of the University. The Universal Declaration of Human Rights (UDHR) was approved in the United Nations General Assembly in december 1948 and ever since has suffered threats and violations, which makes the action of many sectors of society necessary in order to ensure and to enhance such rights. The university is a place of innovation, but it can also reflect some social problems. It is intended in this essay to connect the actions developed by ACPE USP with the perception of the actions that potencialize the Human Rights (HR). After a brief contextualization about the students movement, it is exposed some action from the ACPE USP that ratifies and promotes the HR in the same way that UDHR guides and grounds the action of ACPE USP.
\end{abstract}

KEYWORDs: Human rights; Students movement; Physical education.

\title{
Referências
}

1. Organização das Nações Unidas. Declaração Universal dos Direitos Humanos. Assembleia Geral das Nações Unidas em Paris. 10 dez 1948.

2. Saura SC, Rocco Junior AJ. Núcleo de Direitos Humanos da EEFE-USP: implantação, desenvolvimento e diálogos interunidades. Rev Bras Educ Fís Esporte. 2020;34(Esp):109-116. Disponível em: https://doi.org/10.11606/issn.19814690.v34i0p109-116.

3. Silveira SR, Freudenheim AM, Bassi P, Oliveira JA. Núcleo de Direitos Humanos da Escola de Educação Física e Esporte da USP: uma perspectiva educativa. Rev Bras Educ Fís Esporte. 2020;34(Esp):1-9. Disponível em: https://doi.org/10.11606/ issn.1981-4690.v34i0p1-9.

4. Neto PAF, Neto JSF. Violação dos direitos humanos durante o Apartheid, bem como a importante participação da ONU para abolir tal sistema. Rev Jus Navigandi. 2016.

5. Instituto Brasileiro de Geografia e Estatística. Pesquisa Nacional por Amostra de Domicílios. PNAD. Diretoria de Pesquisas. Coordenação de Trabalho e Rendimento. 2014-2015.

6. Instituto Brasileiro de Geografia e Estatística. Pesquisa de Informaçóes Básicas Municipais - MUNIC. 2018.

7. Escritório USP Mulheres. Interaçóes na USP: Primeiros resultados da Pesquisa. São Paulo. Jun. 2018. Disponível em: http://uspmulheres.usp.br/wp-content/uploads/sites/145/2018/07/INTERA\%C3\%87\%C3\%95ES-NA-USP_final_ publica\%C3\%A7\%C3\%A3o2407.pdf.

8. Fiegenbaum J, Machado NTG, Scheneider P. Movimento estudantil universitário: história do Diretório Central de Estudantes da Univates. Ed. Univates. Lajeado. 2012.

9. Romagnoli LH., Gonçalves TA. Volta da UNE. De Ibiúna a Salvador. Alfa-Omega. 1979. Disponível em: http://une.org. br/wp-content/uploads/2015/04/A-Volta-da-UNE.pdf. 
Vale PHR, et al.

10. Diretório Central de Estudantes. Caderno de história do movimento estudantil. Universidade de Sáo Paulo: Diretório Central de Estudantes, 1979.

11. Ferreira MG. Movimento estudantil de Educação Física: em busca de raízes históricas, uma breve reflexão. Caderno de Debates, v. 3. ExNEEF. Jul 1995.

12. Taffarel CNZ. Dossiê Executiva Nacional dos Estudantes de Educaçáo Física - ExNEEF. LEPEL - Grupo de Estudo e Pesquisa em Educação Física, Esporte e Lazer. FACED UFBA. Salvador/BA. 2020.

13. Comissão da Verdade do Estado de São Paulo "Rubens Paiva”. ALESP. Relatório - Tomo I - Parte II. Perseguição ao Movimento Estudantil Paulista. Disponível em: http://comissaodaverdade.al.sp.gov.br/relatorio/tomo-i/downloads/I_Tomo_Parte_2_ Perseguicao-ao-Movimento-Estudantil-Paulista.pdf. Acesso em: 30 nov 2020.

14. De Andrade NC, De Santana PVSA. Resistência do movimento estudantil na ditadura militar brasileira. Centro Universitário UNIFACIG. 2019.

15. Brasil. Lei no 7.395, de 31 de outubro de 1985 [Internet]. Disponível em: http://www.planalto.gov.br/ccivil_03/ leis/17395.htm.

16. Nobrega CCS. Por uma educação física antirracista. Rev Bras Educ Fís Esporte. 2020;34(Esp):51-61. Disponível em: https://doi.org/10.11606/issn.1981-4690.v34i0p51-61.

\begin{tabular}{r|r} 
ENDEREÇO & \\
Pedro Henrique Rodrigues do Vale & \\
Universidade de São Paulo & \\
Escola de Educação Física e Esporte & Recebido: 04/01/2021 \\
Campus Cidade Universitária & Aceito: 06/01/2021 \\
Av. Prof. Mello Moraes, 65 & \\
05508-030 - São Paulo - SP - Brasil & \\
E-mail: phr_111@usp.br &
\end{tabular}

